\title{
Metabolite Profile Resulting from the Activation/Inactivation of 1-Methyl-4-phenyl-1,2,3,6-tetrahydropyridine and 2-Methyltetrahydro- $\beta$-carboline by Oxidative Enzymes
}

\author{
Tomás Herraiz, Hugo Guillén, and Juan Galisteo \\ Instituto de Ciencia y Tecnología de Alimentos y Nutrición (ICTAN), Consejo Superior de Investigaciones Científicas (CSIC), \\ Juan de la Cierva 3, 28006 Madrid, Spain
}

Correspondence should be addressed to Tomás Herraiz; therraiz@ictan.csic.es

Received 30 April 2013; Accepted 3 July 2013

Academic Editor: Y. James Kang

Copyright (C) 2013 Tomás Herraiz et al. This is an open access article distributed under the Creative Commons Attribution License, which permits unrestricted use, distribution, and reproduction in any medium, provided the original work is properly cited.

\begin{abstract}
Metabolic enzymes are involved in the activation/deactivation of the 1-methyl-4-phenyl-1,2,3,6-tetrahydropyiridine (MPTP) neurotoxin and its naturally occurring analogs 2 -methyltetrahydro- $\beta$-carbolines. The metabolic profile and biotransformation of these protoxins by three enzymes, monoamine oxidase (MAO), cytochrome P450, and heme peroxidases (myeloperoxidase and lactoperoxidase), were investigated and compared. The metabolite profile differed among the enzymes investigated. MAO and heme peroxidases activated these substances to toxic pyridinium and $\beta$-carbolinium species. MAO catalyzed the oxidation of MPTP to 1-methyl-4-phenyl-2,3-dihydropyridinium cation $\left(\mathrm{MPDP}^{+}\right)$, whereas heme peroxidases catalyzed the oxidation of $\mathrm{MPDP}^{+}$to 1-methyl-4-phenylpyridinium $\left(\mathrm{MPP}^{+}\right)$and of 2-methyltetrahydro- $\beta$-carboline to 2-methyl-3,4-dihydro- $\beta$-carbolinium cation $\left(2-\mathrm{Me}-3,4-\mathrm{DH} \beta \mathrm{C}^{+}\right)$. These substances were inactivated by cytochrome P450 2D6 through $N$-demethylation and aromatic hydroxylation (MPTP) and aromatic hydroxylation (2-methyltetrahydro- $\beta$-carboline). In conclusion, the toxicological effects of these protoxins might result from a balance between the rate of their activation to toxic products (i.e., $N$-methylpyridinium$\mathrm{MPP}^{+}$and $\mathrm{MPDP}^{+}$- and $N$-methyl- $\beta$-carbolinium $-\beta \mathrm{C}^{+}-$) by MAO and heme peroxidases and the rate of inactivation (i.e., $N$ demethylation, aromatic hydroxylation) by cytochrome P450 $2 \mathrm{D} 6$.
\end{abstract}

\section{Introduction}

The causative factors of neurodegenerative diseases such as Parkinson's disease (PD) remain unknown, although the involvement of environmental and/or endogenous neurotoxins is being increasingly considered [1-3]. Exposure to 1methyl-4-phenyl-1,2,3,6-tetrahydropyridine (MPTP), a contaminant found in "synthetic heroin," produces neurotoxicity in humans, and this neurotoxin is commonly used to generate experimental parkinsonism in animal models [4-7]. MPTP crosses the blood-brain barrier and is bioactivated enzymatically to give 1-methyl-4-phenylpyridinium $\left(\mathrm{MPP}^{+}\right)$ $[1,8,9]$, which is selectively uptaken into dopaminergic cells via dopamine-activated transporter (DAT) and produces inhibition of mitochondrial complex I, energy depletion, and cell death [8] (Figure 1). Besides its use in experimental models of neurotoxicity, the toxic outcome caused by MPTP is a matter of investigation due to the differences in response among experimental models $[10,11]$. This might result from a change in the balance between the rate of metabolism to toxic products $\left(\mathrm{MPP}^{+}\right.$and $\left.\mathrm{MPDP}^{+}\right)$(activation) and the rate of detoxification (inactivation) [12-16]. MPTP is metabolized by enzymes such as cytochrome P450, and this could affect the outcome of this neurotoxin [12, 14, 17-19].

Humans are not usually exposed to MPTP but are exposed to some structural analogs such as the $\beta$-carboline alkaloids $[20-22] . \beta$-Carbolines appear in foods and are absorbed into the human body and brain, where they may exert psychopharmacological and toxic effects [23-28]. These compounds might follow a toxicological pattern similar to that of MPTP (Figure 1). Firstly, these alkaloids could be bioactivated to $N$-methyl derivatives and then oxidized (aromatized) to pyridinium-like $\beta$-carbolinium species $[15,20,21,29] . \beta$-Carbolinium $\left(\beta \mathrm{C}^{+}\right)$species share several 


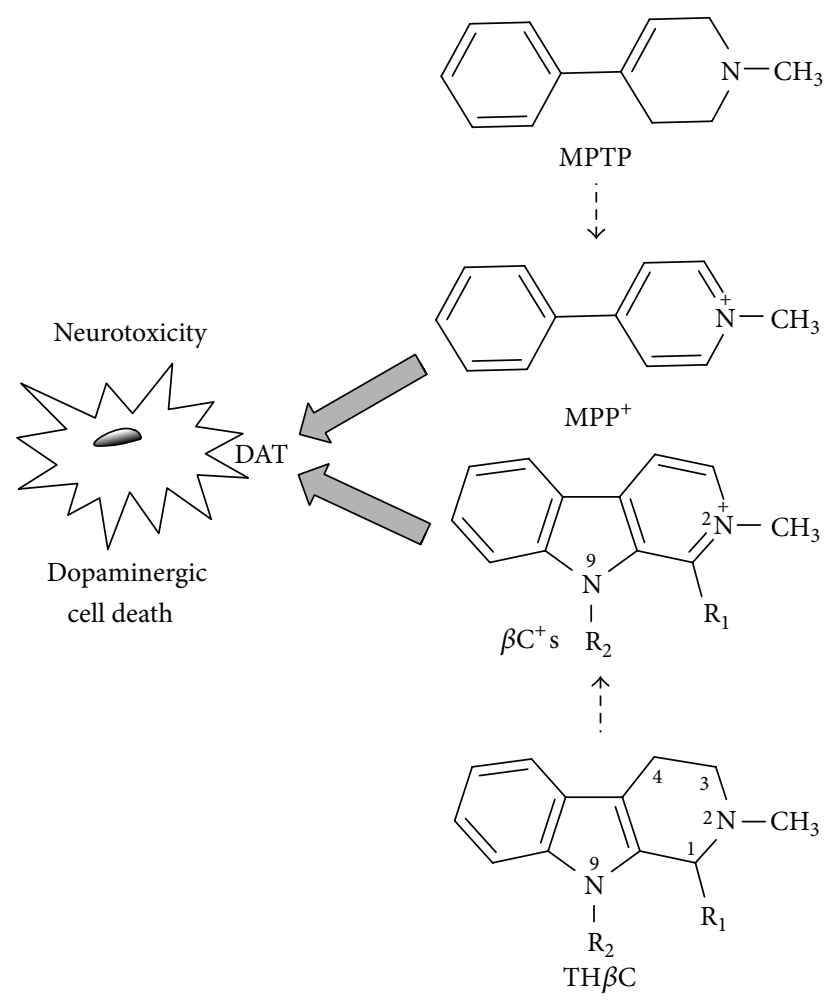

FIgURE 1: Activation of MPTP to the directly acting neurotoxin $\mathrm{MPP}^{+}$, which is uptaken by dopaminergic cells via DAT (dopamine active transporter) and produces neurotoxicity and cell death. $\beta$-Carbolinium cations $\left(\beta \mathrm{C}^{+}\right)$are toxic analogs of $\mathrm{MPP}^{+}$that may arise from 2 methyl-1,2,3,4-tetrahydro- $\beta$-carbolines.

functional and toxicological properties with 1-methyl-4-phenylpyridinium $\left(\mathrm{MPP}^{+}\right)$, which is the metabolite involved in MPTP neurotoxicity [30-32], and were postulated as potential slow-acting neurotoxins $[33,34]$. Remarkably, $N$-methyl$\beta$-carbolinium species such as $N$-methylnorharmanium (2$\left.\mathrm{Me}-\beta \mathrm{C}^{+}\right)$and 2,9-dimethylnorharmanium $\left(2,9-\mathrm{diMe}-\beta \mathrm{C}^{+}\right)$ have been detected in postmortem human brains [34-36] and found in higher proportion in cerebrospinal fluid of patients with neurodegenerative diseases (PD) [35].

The toxicological outcome of MPTP and $\beta$-carbolines will depend on the metabolic profile produced by key enzymes leading to the activation/inactivation of these protoxins [21]. Therefore, studying the activation/inactivation (biotransformation) of MPTP and its naturally occurring analogs by metabolic enzymes is a matter of current interest in order to explain the toxicological features of these substances. It could lead to the identification of the enzyme responsible for activation and inactivation as well as the metabolites produced, and it may also suggest interindividual differences. In this regard, the purpose of this research was to study in a comparative way the metabolic profile generated from MPTP and its naturally occurring analog 2 -methyltetrahydro- $\beta$ carboline by three metabolic enzymes: monoamine oxidase (MAO), heme peroxidase, and cytochrome P450 (2D6). Monoamine oxidase (MAO) is a flavoenzyme located at the outer membranes of mitochondria in the human brain and peripheral tissues that catalyzes the oxidative deamination of neurotransmitters and xenobiotic amines. MAO appears as two isozymes, MAO-A and $\mathrm{B}$, and plays an important role in the central nervous system and peripheral organs [37]. MAO$\mathrm{A}$ is involved in psychiatric conditions and depression and MAO-B is implicated in neurodegenerative diseases [37-41]. The cytochrome P450 enzymes are mixed-function oxidases involved in the metabolism of drugs and xenobiotics. In particular, the cytochrome P450 2D6 is present in the liver and extrahepatic tissues and participates in the metabolism and toxicity of many drugs with a basic nitrogen. This cytochrome presents strong polymorphism, characterized by poor, intermediate, extensive, and ultrarapid metabolizers, and it is currently being considered in relation to neurodegenerative diseases [17, 42-46]. Heme peroxidases participate in the oxidation of endogenous substrates, drugs, and xenobiotics [47]. Mammalian peroxidases such as myeloperoxidase (MPO), eosinophil peroxidase (EPO), and lactoperoxidase (LPO) are found in neutrophils, eosinophils, and secretory cells of the exocrine glands and participate in antimicrobial and antiinflammatory processes. MPO occurs in activated microglia at sites of degenerative diseases [48-50]. Peroxidases in the substantia nigra may produce toxic substances and might be involved in PD and neurodegeneration [51, 52].

\section{Material and Methods}

2.1. Chemicals and Enzymes. 1-Methyl-4-phenyl-1,2,3,6-tetrahydropyridine (MPTP) hydrochloride (caution: MPTP is a neurotoxin and should be handled with appropriate precautions), 1-methyl-4-phenyl-2,3-dihydropyridinium $\left(\mathrm{MPDP}^{+}\right)$ 
perchlorate, 1-methyl-4-phenylpyridinium $\left(\mathrm{MPP}^{+}\right)$iodide, 4phenyl-1,2,3,6-tetrahydropyridine hydrochloride (PTP), and NADPH were from Sigma-Aldrich (St. Louis, MO, USA). 2Methyl-1,2,3,4-tetrahydro- $\beta$-carboline hydrochloride (2-Me$\mathrm{TH} \beta \mathrm{C}$ ), 2-methyl-3,4-dihydro- $\beta$-carbolinium chloride (2$\mathrm{Me}-3,4-\mathrm{DH} \beta \mathrm{C}^{+}$), 2-methyl- $\beta$-carbolinium iodide (2-Me$\left.\beta \mathrm{C}^{+}\right)$, and 4 -( $4^{\prime}$-hydroxyphenyl)-1-methyl-1,2,3,6-tetrahydropyridine hydrochloride (MPTP-OH) were obtained previously [14-16]. Human monoamine oxidases (MAO-A and B) were obtained from BD Gentest Co. (Woburn, MA, USA). Microsomes containing recombinant human cytochrome P450 2D6*1+cytochrome P450 oxidoreductase produced from baculovirus infected-insect cells were obtained from $\mathrm{BD}$ Gentest Co. (Woburn, MA, USA). Bovine lactoperoxidase (LPO) and human myeloperoxidase (MPO) were obtained from Sigma and Calbiochem (Merck), respectively, and the concentration in the assays is determined using the extinction coefficients of Soret bands [53].

\subsection{Enzyme Biotransformation and Metabolic Profile}

2.2.1. MAO Enzymes. $0.2 \mathrm{~mL}$ reaction mixtures in $75 \mathrm{mM}$ buffer phosphate ( $\mathrm{pH}$ 7.4) containing human MAO-A or -B $(0.01-0.2 \mathrm{mg} / \mathrm{mL}$ protein) and $\operatorname{MPTP}(50,250 \mu \mathrm{M})$ or 2-methyl-1,2,3,4-tetrahydro- $\beta$-carboline $(50,250 \mu \mathrm{M})$ were incubated $\left(37^{\circ} \mathrm{C}, 40 \mathrm{~min}\right)$; the reaction was stopped by the addition of $2 \mathrm{~N} \mathrm{NaOH}(75 \mu \mathrm{L})$ and $70 \%$ perchloric acid $(25 \mu \mathrm{L})$ subsequently centrifuged $\left(9000 \mathrm{rpm}, 5^{\circ} \mathrm{C}\right)$, and $20 \mu \mathrm{L}$ of the supernatant injected into the HPLC. The metabolic profile was analyzed by HPLC-DAD, and the metabolites identified by mass spectrometry (ESI). Incubations were performed at least in duplicate.

2.2.2. Cytochrome P450 2D6. $0.2 \mathrm{~mL}$ reaction mixtures in $75 \mathrm{mM}$ phosphate buffer ( $\mathrm{pH} 7.4)$ containing human cytochrome P450 2D6 (7 pmol P450) and MPTP (50, $250 \mu \mathrm{M})$ or 2 -methyl-1,2,3,4-tetrahydro- $\beta$-carboline $(50,250 \mu \mathrm{M})$, and NADPH $(1 \mathrm{mM})$ were incubated at $37^{\circ} \mathrm{C}, 25 \mathrm{~min}$. The reaction was stopped with a mixture of methanol and perchloric acid $(1: 1)(50 \mu \mathrm{L})$, centrifuged at $10000 \mathrm{rpm}$ for $10 \mathrm{~min}$, and $5^{\circ} \mathrm{C}$, and $20 \mu \mathrm{L}$ of the supernatant injected into the HPLC. The metabolic profile was analyzed by HPLC-DAD, and the metabolites identified by mass spectrometry (ESI). Incubations were performed at least in duplicate.

2.2.3. Heme Peroxidases. $0.5 \mathrm{~mL}$ reaction mixtures in $50 \mathrm{mM}$ phosphate buffer ( $\mathrm{pH} 7$ ), containing lactoperoxidase (LPO) $(0.18 \mu \mathrm{M})$ or myeloperoxidase (MPO) $(0.013 \mu \mathrm{M})$, and MPTP $(50,250 \mu \mathrm{M}), \mathrm{MPDP}^{+}(50,250 \mu \mathrm{M})$ or 2-methyl-1,2,3,4-tetrahydro- $\beta$-carboline $(50,250 \mu \mathrm{M})$, and $\mathrm{H}_{2} \mathrm{O}_{2}(25 \mu \mathrm{M})$ were incubated at $37^{\circ} \mathrm{C}, 40 \mathrm{~min}$. Following the addition of $\mathrm{HClO}_{4}+$ methanol (1/1) $(10 \% \mathrm{v} / \mathrm{v}$ of reaction volume), the tubes were centrifuged at $10000 \mathrm{rpm}, 10 \mathrm{~min}$, and $20 \mu \mathrm{L}$ of the supernatant injected into the HPLC. The metabolic profile was analyzed by HPLC-DAD, and the metabolites identified by mass spectrometry (ESI). Incubations were performed at least in duplicate.
2.2.4. RP-HPLC Chromatographic Analysis and Mass Spectrometry. The chromatographic analysis of the reaction products from enzyme incubations was performed by RP-HPLC with $u v-D A D$ and fluorescence detection using an HPLC 1050 (Hewlett Packard) with a Diode Array Detector (DAD) and a 1046A-fluorescence detector $[14,15]$. A $150 \mathrm{~mm} \times 3.9 \mathrm{~mm}$, $4 \mu \mathrm{m}$, Nova-pak C18 column (Waters, Milford, MA, USA) was used for chromatographic separation. Chromatographic conditions were buffer A: $50 \mathrm{mM}$ ammonium phosphate buffer ( $\mathrm{pH} 3$ for MAO and peroxidase assays or $\mathrm{pH} 5.5$ for cytochrome P450 2D6) and buffer B: $20 \%$ of A in acetonitrile. Gradient was programmed from $0 \%(100 \% \mathrm{~A})$ to $32 \% \mathrm{~B}$ at $8 \mathrm{~min}$ and $90 \% \mathrm{~B}$ at $15 \mathrm{~min}$. The flow rate was $1 \mathrm{~mL} / \mathrm{min}$, the column temperature was $40^{\circ} \mathrm{C}$, and the injection volume was $20 \mu \mathrm{L}$. Absorbance detection was set at $355 \mathrm{~nm}$ for analysis of dehydrogenation products such as $\mathrm{MPDP}^{+}$and 2-methyl3,4-dihydro- $\beta$-carbolinium species $\left(2-\mathrm{Me}-\mathrm{DH} \beta \mathrm{C}^{+}\right) ; 280 \mathrm{~nm}$ for analysis of $\mathrm{MPP}^{+} ; 254 \mathrm{~nm}$ for the analysis of 2-methyl$\beta$-carbolinium cation; $280 \mathrm{~nm}$ for 2 -methyltetrahydro- $\beta$ carboline (2-Me-TH $\beta \mathrm{C}$ ) and its metabolites, $243 \mathrm{~nm}$ for PTP, and $254 \mathrm{~nm}$ for MPTP-OH. Calibration curves of absorbance versus concentration were constructed for each metabolite. Identification of metabolites was done by UV (DAD spectra) fluorescence and coelution with authentic standards. Confirmation of the identity was performed with HPLC-ESI-mass spectrometry $[14,15]$. For that, separation was accomplished on a $2.1 \times 150 \mathrm{~mm}$ Zorbax SB-C18 $3.5 \mu \mathrm{m}$ column by using an HPLC-MSD Series 1100 (Hewlett Packard, Santa Clara, CA, USA) working under electrospray ionization positiveion mode. Eluents: (A) formic acid (0.5\%), (B) formic acid $0.5 \%$ in acetonitrile; $80 \% \mathrm{~B}$ in $30 \mathrm{~min}$, flow: $0.25 \mathrm{~mL} / \mathrm{min}$, cone voltage: $70 \mathrm{~V}$, and mass range: 50-600 amu.

\section{Results and Discussion}

The activation and inactivation of MPTP neurotoxin and 2methyltetrahydro- $\beta$-carboline protoxin occur with the participation of key metabolic enzymes. This research studied and compared the metabolic profile generated from these substances by human monoamine oxidase, human cytochrome P450 2D6, and heme peroxidases (Figure 2). Human MAO enzymes (MAO-B) oxidized MPTP to give MPDP and $\mathrm{MPP}^{+}$(Figure 3(a)). The main metabolite arising from MAO and MPTP was MPDP ${ }^{+}$, whereas $\mathrm{MPP}^{+}$was produced through subsequent oxidation of $\mathrm{MPDP}^{+}$(Figure 4(a)). As the pyridinium species are the directly acting neurotoxins in vivo, the oxidation by MAO is considered a key route for the bioactivation of MPTP (Figure 2) [8]. Indeed, inhibitors of MAO-B usually protect against this neurotoxin and can be useful as neuroprotectants [37, 40, 41, 54, 55]. Although human MAO-A was also able to oxidize MPTP in vitro as well, a number of studies have shown that MAO-B is the main isoform involved in this oxidation [54-57].

The neurotoxin MPTP was metabolized by the cytochrome P450 2D6 (Figure 3(b)). Two major metabolites were 4-(4'-hydroxyphenyl)-1-methyl-1,2,3,6-tetrahydropyridine (MPTP-OH) (aromatic hydroxylation) and 4-phenyl-1,2,3,6tetrahydropyridine (PTP) (N-demethylation) (Figure 4(b)). 


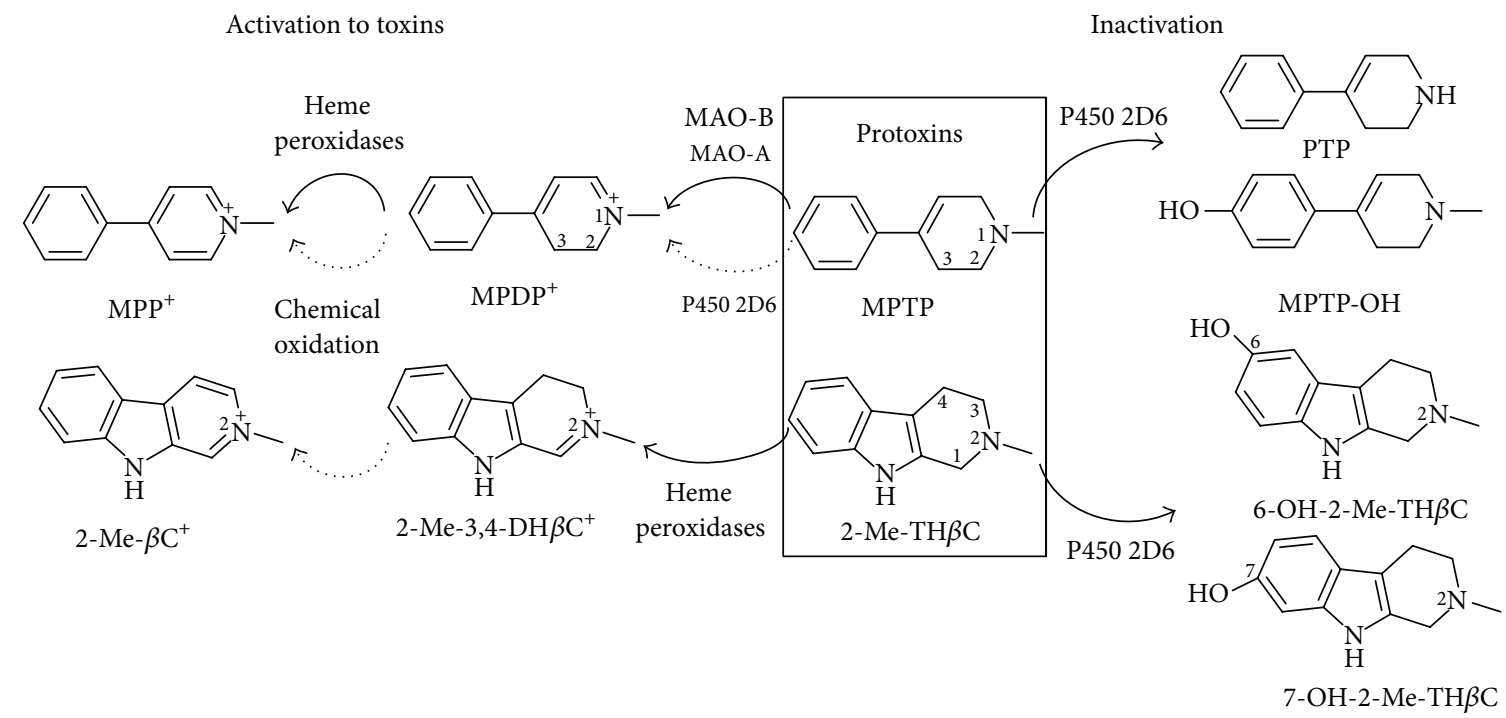

FIGURE 2: Proposed activation and inactivation routes and metabolites from MPTP and 2-methyl-1,2,3,4-tetrahydro- $\beta$-carboline (2-Me$\mathrm{TH} \beta \mathrm{C}$ ) protoxins resulting from human monoamine oxidase (MAO), heme peroxidases (lactoperoxidase and myeloperoxidase), and human cytochrome P450 2D6.

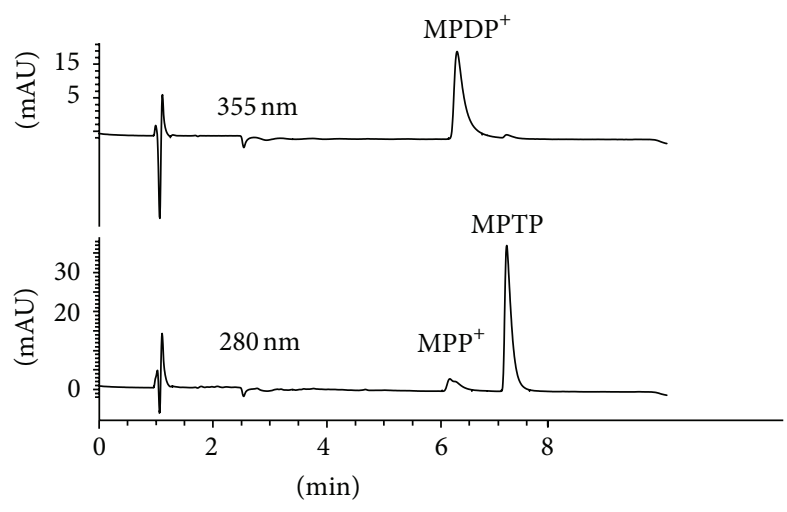

(a)

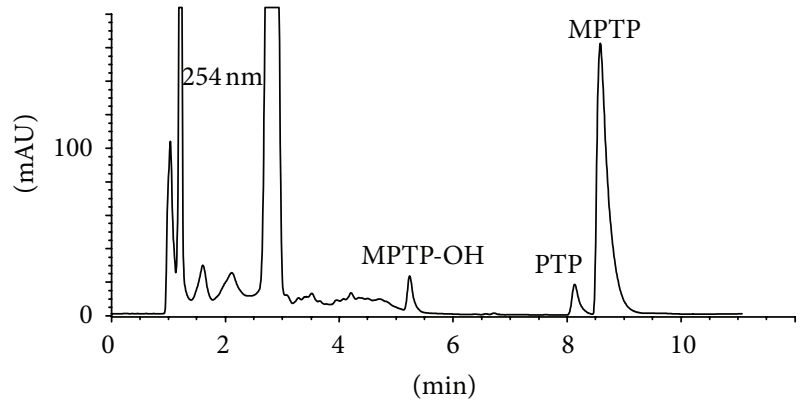

(b)

FIGURE 3: HPLC chromatograms of MPTP oxidized by human MAO-B (a) and MPTP oxidized by human cytochrome P450 2D6 (b). Enzyme assays and chromatographic conditions were as indicated in experimental section.

In addition, the cytochrome P450 2D6 oxidized MPTP to give minor amounts of $\mathrm{MPDP}^{+}$and $\mathrm{MPP}^{+}$, although this conversion was of lower efficiency compared with MAO (Figure 4(c)). On the other hand, two heme peroxidases (lactoperoxidase and myeloperoxidase) were unable to oxidize MPTP to pyridinium species in the presence of $\mathrm{H}_{2} \mathrm{O}_{2}$, indicating that MPTP was not a substrate of these kinds of oxidative enzymes. Interestingly, however, these peroxidases accelerated the oxidation of $\mathrm{MPDP}^{+}$to $\mathrm{MPP}^{+}$(Figure 6(c)). Although $\mathrm{MPDP}^{+}$could be auto oxidized or disproportionated to give $\mathrm{MPP}^{+}[15,58]$ as reported in Figure 2, peroxidases increased this oxidation when compared to controls. Then, activation of the $\mathrm{MPDP}^{+}$to the directly acting neurotoxin $\mathrm{MPP}^{+}$could be facilitated by heme peroxidases, and this might have further implications for the neurotoxicity of this and related substances (Figure 2).
In a search for analogies with MPTP, the naturally occurring $\beta$-carboline 2 -methyltetrahydro- $\beta$-carboline was metabolized by the former enzymes (Figure 2). Human MAO enzymes (MAO-A or -B) did not afford any detectable metabolites of oxidation (i.e., $\beta$-carbolinium species). Therefore, MPTP and its $\beta$-carboline analogs behaved differently regarding the metabolism by MAO, suggesting that they differ in the activation pathway (Figure 2). Instead, the cytochrome P450 2D6 was able to metabolize the tetrahydro$\beta$-carboline that was hydroxylated to two metabolites identified as 6-hydroxy-2-methyl-1,2,3,4-tetrahydro- $\beta$-carboline (6-OH-2-Me-TH $\beta \mathrm{C}$ ) and 7-hydroxy-2-methyl-1,2,3,4-tetrahydro- $\beta$-carboline (7-OH-2-Me-TH $\beta \mathrm{C}$ ) (Figures $5(\mathrm{a})$ and 6(a)). These polar metabolites could be considered detoxification metabolites, and, in that case, the cytochrome P450 2D6 can participate in an inactivation route of 


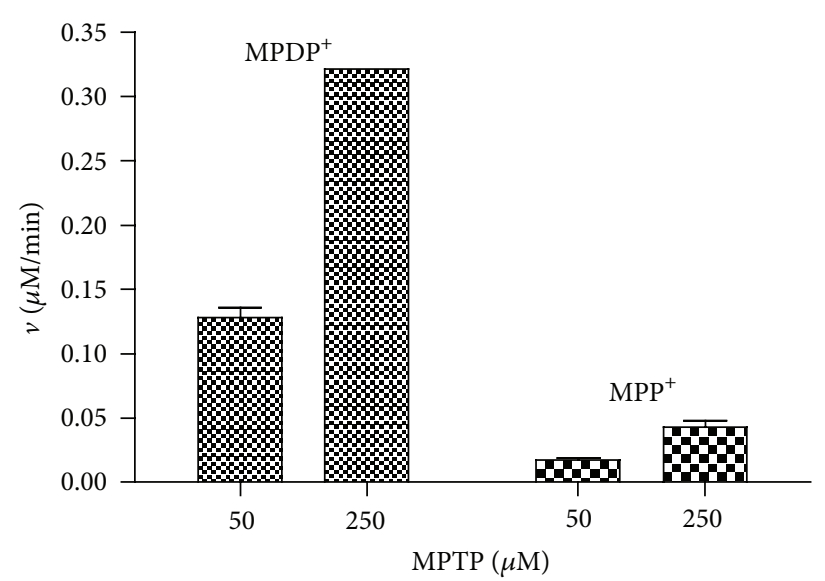

(a) MAO-B

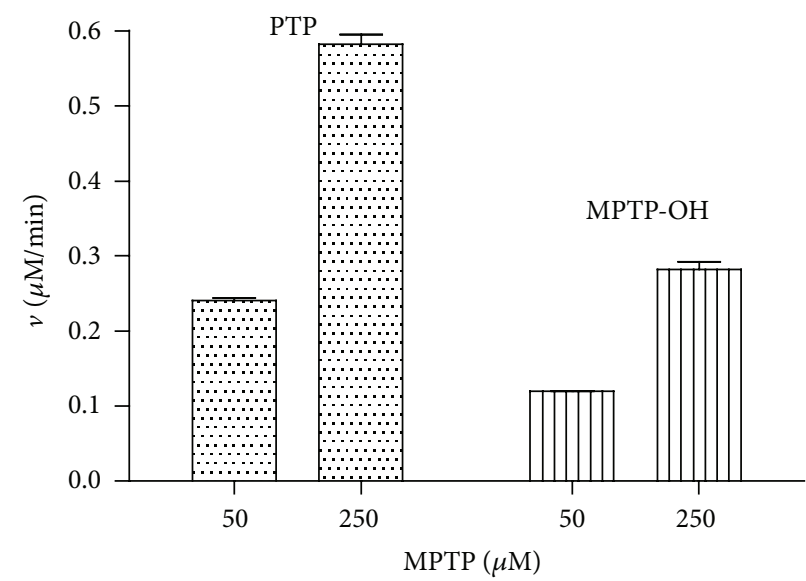

(b) P450 2D6

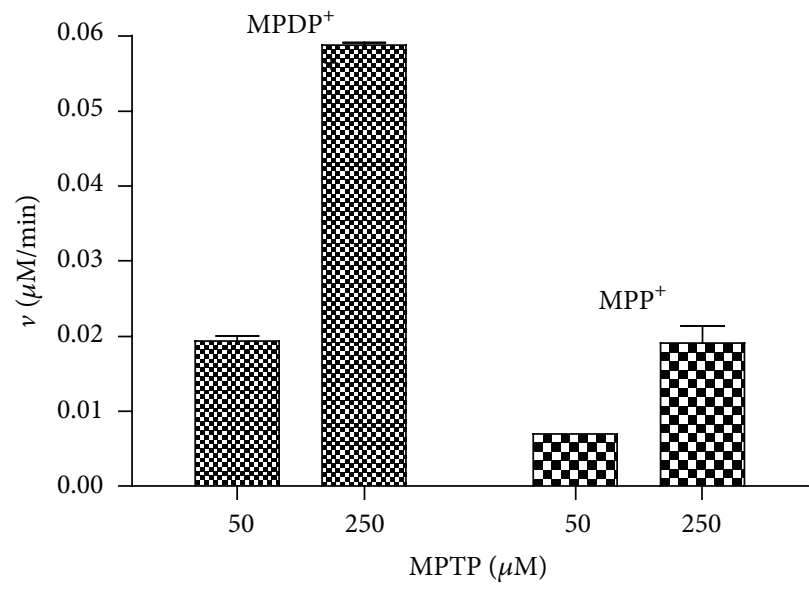

(c) P450 2D6

FIGURE 4: Metabolites and rates produced from MPTP neurotoxin ( 50 and $250 \mu \mathrm{M})$ by human MAO-B $(0.05 \mathrm{mg} / \mathrm{mL}$ protein) (a) and human cytochrome P450 2D6 (b) and (c). Enzyme assays were as indicated in experimental section.

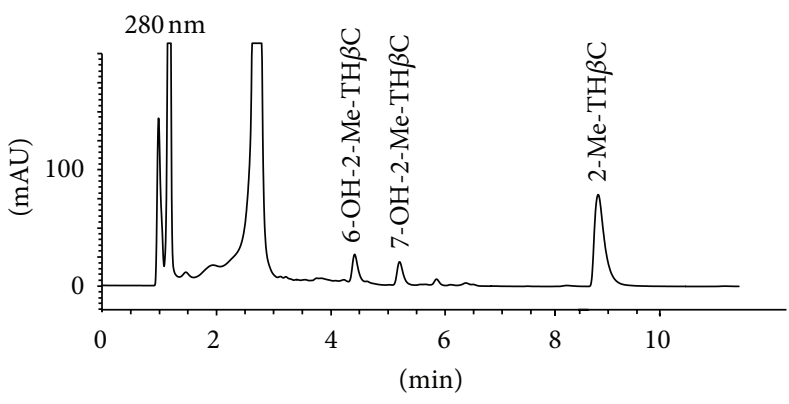

(a)

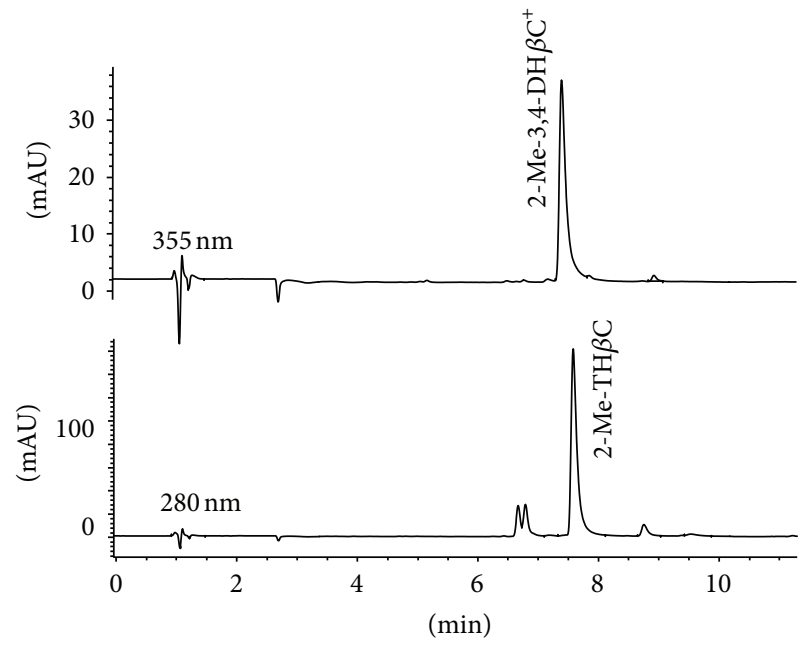

(b)

FIGURE 5: HPLC chromatograms of metabolites from 2-methyl-1,2,3,4-tetrahydro- $\beta$-carboline incubated with cytochrome P450 2D6 (a) and myeloperoxidase (b). Enzyme assays and chromatographic conditions were as indicated in experimental section. 


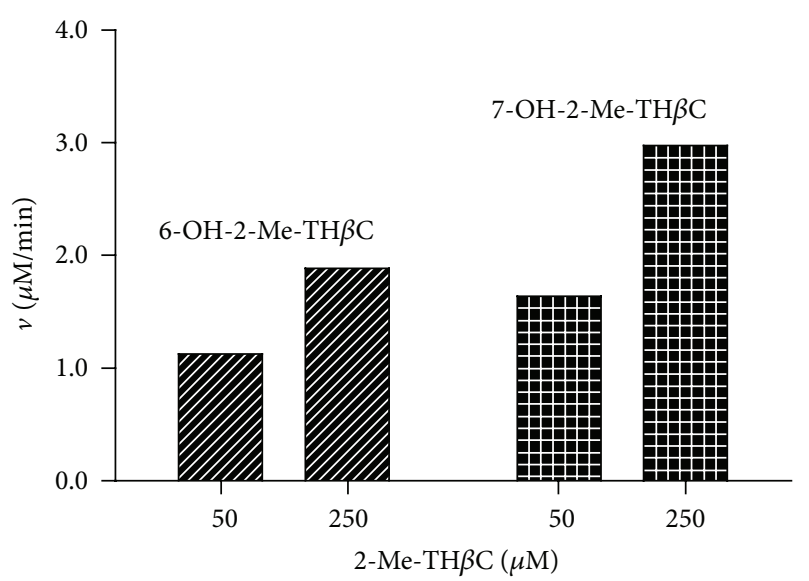

(a) P450 2D6

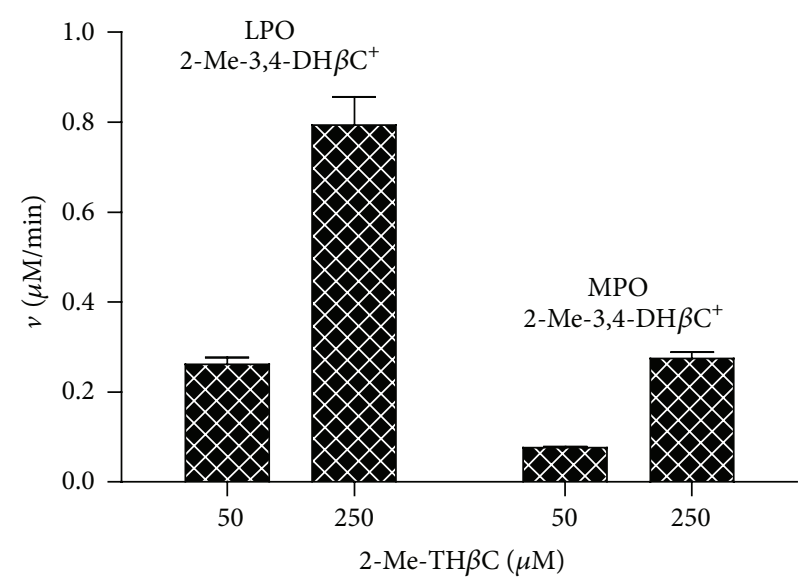

(b) Heme peroxidases

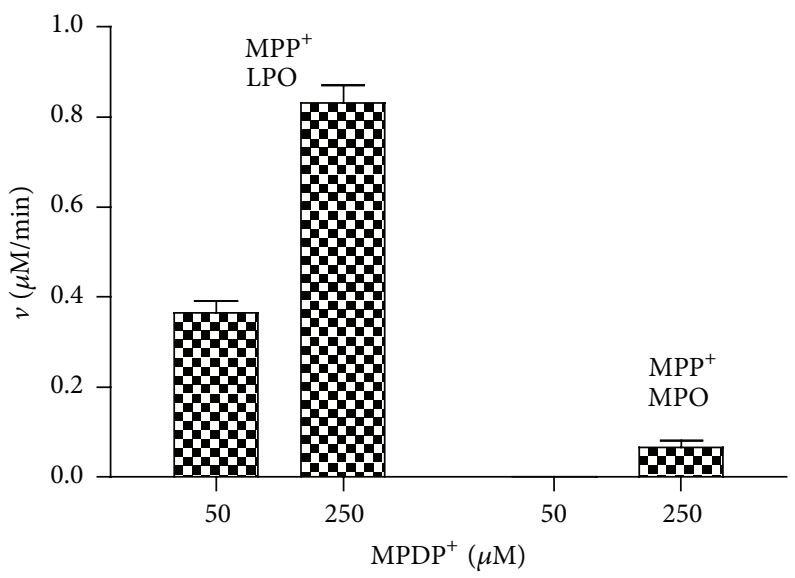

(c) Heme peroxidases

Figure 6: Metabolites and rates produced from 2-methyl-1,2,3,4-tetrahydro- $\beta$-carboline (2-Me-TH $\beta$ C) by cytochrome P450 $2 \mathrm{D} 6$ (a) and lactoperoxidase (LPO) and myeloperoxidase (MPO) (b). (c) Corresponds to the formation of $\mathrm{MPP}^{+}$from MPDP ${ }^{+}$as catalyzed by peroxidases LPO and MPO (the corresponding controls with $\mathrm{H}_{2} \mathrm{O}_{2}$ and no enzyme are subtracted). Enzyme assays were as indicated in experimental section.

2-methyltetrahydro- $\beta$-carboline, in a similar way to MPTP. On the other hand, 2 -methyltetrahydro- $\beta$-carboline was oxidized in a reaction catalyzed by heme peroxidases in the presence of $\mathrm{H}_{2} \mathrm{O}_{2}$ (Figure 5(b)). This tetrahydro- $\beta$-carboline was oxidized by lactoperoxidase and myeloperoxidase to the corresponding 2-methyl-3,4-dihydro- $\beta$-carbolinium cation (2Me-3,4-DH $\beta \mathrm{C}^{+}$) (Figure 6(b)) and traces detected of the fully aromatic $\beta$-carbolinium cation (2-methyl- $\beta$-carbolinium cation). The $\beta$-carbolinium species are neurotoxic substances $[30,33]$, and therefore this oxidation may represent a new route of activation of naturally occurring 2methyltetrahydro- $\beta$-carbolines, which could be of significance for the toxicological fate of these substances (Figure 2). These results agree with the ability of tetrahydro- $\beta$-carbolines to be oxidized to dihydro- and aromatic $\beta$-carbolines [27, 59] and also with the participation of these substrates in a reduction of redox intermediates of peroxidases [53].

MPTP induces parkinsonism in humans and animal models, whereas the $\beta$-carbolines were postulated as possible toxins involved in neurodegeneration [20]. As seen in Figure 2, biochemical reactions leading to the activation/inactivation of these substances are critical for their toxicological outcome. A so-called "activation" to toxic pyridinium or $\beta$-carbolinium species is required for toxicity, whereas an "inactivation" may influence the fate of these protoxins in the body. Differences in the activation/inactivation balance and consequently in the response to these substances may arise from differences in the enzymes involved. The toxic response to MPTP largely varies between species [7, 10, 11], and this might result from differences in the expression and activity of metabolic enzymes $[49,50,60,61]$ producing a different ratio between toxic and inactive metabolites. The results reported here indicate substantial differences among the enzymes involved and profile (Figure 2). While MAO enzymes were responsible for the activation of MPTP to give toxic pyridinium species, heme peroxidases were activators of 2 -methyltetrahydro- $\beta$-carbolines to pyridinium-like carbolinium toxins and MAO played no role. Although heme peroxidases were not involved in the MPTP activation, these enzymes catalyzed the oxidation step from $\mathrm{MPDP}^{+}$to $\mathrm{MPP}^{+}$. Thus, heme peroxidases like myeloperoxidase may accelerate the flow from $\mathrm{MPDP}^{+}$(i.e., produced by MAO) to $\mathrm{MPP}^{+}$. With these results in mind, peroxidases might play a role in the bioactivation of these or related protoxins, resulting 
in increased toxicity (Figure 2) [15]. In this regard, the potential involvement of peroxidases in neurodegeneration and Parkinson's disease has been already suggested [50-52, 62]. Myeloperoxidase occurs at sites of degenerative diseases and neuroinflammation and increases in Alzheimer's disease $[48,63]$, and its ablation mitigated PD produced by MPTP neurotoxin in animals [49].

MPTP and 2-methyltetrahydro- $\beta$-carbolines differed in the activation route to toxic metabolites (i.e., MAO versus heme peroxidase). However, both were metabolized by human cytochrome P450 2D6. This enzyme carried out the metabolism of MPTP by $N$-demethylation and aromatic hydroxylation and 2 -methyltetrahydro- $\beta$-carboline by aromatic hydroxylation (Figure 2 ). The involvement of cytochrome P450 2D6 in detoxification is relevant, and some studies have reported an association between cytochrome P450 2D6 polymorphism and Parkinson's disease (PD) $[44,64]$. This enzyme is lower in PD patients, which may reduce the ability of those patients to inactivate $\mathrm{PD}$-causing neurotoxicity [64]. For example, exposure to pesticides increases the incidence of $\mathrm{PD}$, and this risk was even higher in subjects with a poor metabolizer 2D6 genotype exposed to pesticides $[3,45]$. In contrast to pyridinium species (i.e., $\mathrm{MPDP}^{+}$and $\mathrm{MPP}^{+}$) produced by MAO, the MPTP-OH and PTP metabolites arising from cytochrome P450 2D6 are thought to be devoid of neurotoxicity [12, 65]. Therefore, cytochrome P450 2D6 competes with MAO enzymes in favour of an inactivation route of the MPTP neurotoxin [14]. Results in Figure 4 also showed that P450 2D6 slightly activated MPTP to the pyridinium species, $\mathrm{MPDP}^{+}$and $\mathrm{MPP}^{+}$. Recently, a mitochondrial cytochrome P450 2D6 was reported that was able to carry out the activation of MPTP to pyridinium species $\left(\mathrm{MPDP}^{+}\right.$and $\mathrm{MPP}^{+}$) suggesting a role for this enzyme in the activation process and toxicity [17]; however, this conversion appeared to be of lower significance compared with MAO [14].

$\beta$-Carbolines abound in plants and foods and appear in biological tissues including the brain $[25,27,66,67]$. They exert psychopharmacological and behavioural effects [23$27,54,66,68]$. An involvement of tetrahydro- $\beta$-carbolines (and/or $\beta$-carbolines) as proneurotoxins is based on the fact that these compounds are $N$-methylated to $N(2)$ methyltetrahydro- $\beta$-carbolines which can be subsequently oxidized to $N(2)$-methyl- $\beta$-carbolinium species $[20,21,29$, $33,69]$. $N$-Methylation of tetrahydro- $\beta$-carbolines $(\mathrm{TH} \beta \mathrm{C})$ is catalyzed by brain $N$-methyltransferases [69], and 2methyltetrahydro- $\beta$-carboline has been detected in rat brain [70]. However, this sequence lacks a step of activation to $\beta$-carbolinium species. 2-Methyltetrahydro- $\beta$-carboline is not neurotoxic [65] but it could be oxidized (activated) to toxic $\beta$-carbolinium cation $\left(\beta \mathrm{C}^{+}\right)$by heme peroxidases $/ \mathrm{H}_{2} \mathrm{O}_{2}$ (lactoperoxidase and myeloperoxidase) (Figures 2 and 6 ). $\beta$ Carbolinium species resemble $\mathrm{MPP}^{+}$in many of their toxicological features. $N$-Methyl- $\beta$-carbolinium cation (2-Me$\left.\beta \mathrm{C}^{+}\right)$and $N, N$-dimethyl- $\beta$-carbolinium cation (2,9-diMe$\beta \mathrm{C}^{+}$) are neurotoxins producing irreversible striatal lesions $[31,71]$. These carbolinium species $\left(2-\mathrm{Me}-\beta \mathrm{C}^{+}\right.$and $2,9-\mathrm{diMe}-$ $\beta \mathrm{C}^{+}$) were found in normal and parkinsonian brains [3436] and appeared in higher proportion in the brain and cerebrospinal fluid of PD patients [34,35]. As the cytochrome P450 2D6 contributes to the metabolism of tetrahydro- $\beta$ carbolines to hydroxylated metabolites $[14,43]$, this route could be competitive against the oxidation by peroxidases and the $N$-methylation by $N$-methyltransferases $[14,15,21]$. The biotransformation of $\beta$-carbolines by cytochrome $\mathrm{P} 450$ 2D6 may influence the outcome of these substances as eventual protoxins and generate differences depending on enzyme polymorphism.

In summary, these results indicate that activation/inactivation of MPTP and 2-methyltetrahydro- $\beta$-carboline protoxins depends on three key oxidative enzymes that are crucial for toxicity and detoxification. MPTP relays on MAO enzymes for activation (toxicity) with a possible role for heme peroxidases. However, it relays on cytochrome P450 2D6 for inactivation. In contrast, 2 -methyltetrahydro- $\beta$-carbolines depend on heme peroxidases for activation to toxic carbolinium species and cytochrome P450 2D6 for detoxification with no role played by MAO enzymes. It can be concluded that the degree of toxicity caused by those protoxins may result from a balance between the rate of activation to toxic products (i.e., $N$-methylpyridinium- $\mathrm{MPP}^{+}$and $\mathrm{MPDP}^{+}$- and $N$-methyl$\beta$-carbolinium $-\beta \mathrm{C}^{+}-$) and the rate of inactivation (detoxification) (i.e., $N$-demethylation, aromatic hydroxylation). As the enzymes involvement may vary in expression and activity between persons, major differences in the toxicological outcome of these protoxins are foreseen.

\section{Conflict of Interests}

The authors declare no competing financial interest. They do not have a financial relation with the commercial identities mentioned in the paper.

\section{Acknowledgments}

The authors thank Projects 200470E658 (CSIC) and AGL2010-18448 for financial support.

\section{References}

[1] J. W. Langston, P. Ballard, J. W. Tetrud, and I. Irwin, "Chronic parkinsonism in humans due to a product of meperidineanalog synthesis," Science, vol. 219, no. 4587, pp. 979-980, 1983.

[2] J. R. Cannon and J. T. Greenamyre, "The role of environmental exposures in neurodegeneration and neurodegenerative diseases," Toxicological Sciences, vol. 124, no. 2, pp. 225-250, 2011.

[3] A. Moretto and C. Colosio, "Biochemical and toxicological evidence of neurological effects of pesticides: the example of Parkinson's disease," NeuroToxicology, vol. 32, no. 4, pp. 383-391, 2011.

[4] V. Jackson-Lewis and S. Przedborski, "Protocol for the MPTP mouse model of Parkinson's disease," Nature Protocols, vol. 2, no. 1, pp. 141-151, 2007.

[5] S. K. Kidd and J. S. Schneider, "Protective effects of valproic acid on the nigrostriatal dopamine system in a 1-methyl-4-phenyl1,2,3,6-tetrahydropyridine mouse model of Parkinson's disease," Neuroscience, vol. 194, pp. 189-194, 2011. 
[6] R. B. Mythri, J. Veena, G. Harish, B. S. S. Rao, and M. M. S. Bharath, "Chronic dietary supplementation with turmeric protects against 1-methyl-4-phenyl-1,2,3,6-tetrahydropyridinemediated neurotoxicity in vivo: implications for Parkinson's disease," British Journal of Nutrition, vol. 106, no. 1, pp. 63-72, 2011.

[7] F. Blandini and M.-T. Armentero, "Animal models of Parkinson's disease," FEBS Journal, vol. 279, no. 7, pp. 1156-1166, 2012.

[8] J. W. Langston, I. Irwin, E. B. Langston, and L. S. Forno, "1-methyl-4-phenylpyridinium ion $\left(\mathrm{MPP}^{+}\right)$: identification of a metabolite of MPTP, a toxin selective to the substantia nigra," Neuroscience Letters, vol. 48, no. 1, pp. 87-92, 1984.

[9] A. Lehner, M. Johnson, T. Simkins et al., "Liquid chromatographic-electrospray mass spectrometric determination of 1methyl-4-phenylpyridine $\left(\mathrm{MPP}^{+}\right)$in discrete regions of murine brain," Toxicology Mechanisms and Methods, vol. 21, no. 3, pp. 171-182, 2011.

[10] T. Ito, K. Uchida, and H. Nakayama, "Neuronal or inducible nitric oxide synthase (NOS) expression level is not involved in the different susceptibility to nigro-striatal dopaminergic neurotoxicity induced by 1-methyl-4-phenyl-1,2,3,6-tetrahydropyridine (MPTP) between C57BL/6 and BALB/c mice," Experimental and Toxicologic Pathology, vol. 65, no. 1-2, pp. 121125, 2013.

[11] T. Ito, K. Suzuki, K. Uchida, and H. Nakayama, "1-methyl-4phenyl-1,2,3,6-tetrahydropyridine (MPTP)-induced neuroblastic apoptosis in the subventricular zone is caused by 1-methyl4-phenylpyridinium $\left(\mathrm{MPP}^{+}\right)$converted from MPTP through MAO-B," Experimental and Toxicologic Pathology, vol. 64, no. 7-8, pp. 761-765, 2012.

[12] D. E. Gilham, W. Cairns, M. J. I. Paine et al., "Metabolism of MPTP by cytochrome P4502D6 and the demonstration of 2D6 mRNA in human foetal and adult brain by in situ hybridization," Xenobiotica, vol. 27, no. 1, pp. 111-125, 1997.

[13] J. Weissman, A. Trevor, K. Chiba et al., "Metabolism of the nigrostriatal toxin 1-methyl-4-phenyl-1,2,3,6-tetrahydropyridine by liver homogenate fractions," Journal of Medicinal Chemistry, vol. 28, no. 8, pp. 997-1001, 1985.

[14] T. Herraiz, H. Guillén, V. J. Arán, J. R. Idle, and F. J. Gonzalez, "Comparative aromatic hydroxylation and $N$-demethylation of MPTP neurotoxin and its analogs, $N$-methylated $\beta$-carboline and isoquinoline alkaloids, by human cytochrome P450 2D6," Toxicology and Applied Pharmacology, vol. 216, no. 3, pp. 387398, 2006.

[15] T. Herraiz, H. Guillén, and J. Galisteo, "N-methyltetrahydro$\beta$-carboline analogs of 1-methyl-4-phenyl-1,2,3,6-tetrahydropyridine (MPTP) neurotoxin are oxidized to neurotoxic $\beta$ carbolinium cations by heme peroxidases," Biochemical and Biophysical Research Communications, vol. 356, no. 1, pp. 118123, 2007.

[16] S. Modi, D. E. Gilham, M. J. Sutcliffe et al., "1-methyl-4-phenyl1,2,3,6-tetrahydropyridine as a substrate of cytochrome P450 2D6: allosteric effects of NADPH-cytochrome P450 reductase," Biochemistry, vol. 36, no. 15, pp. 4461-4470, 1997.

[17] P. Bajpai, M. C. Sangar, S. Singh et al., "Metabolism of 1-methyl4-phenyl-1,2,3,6-tetrahydropyridine by mitochondrion-targeted cytochrome P450 2D6: implications in Parkinson disease," The Journal of Biological Chemistry, vol. 288, no. 6, pp. 44364451, 2013.

[18] I. H. Hanna, J. A. Krauser, H. Cai, M.-S. Kim, and F. P. Guengerich, "Diversity in mechanisms of substrate oxidation by cytochrome P450 2D6: lack of an allosteric role of NADPHcytochrome $\mathrm{P} 450$ reductase in catalytic regioselectivity," The Journal of Biological Chemistry, vol. 276, no. 43, pp. 3955339561, 2001.

[19] T. Coleman, S. W. Ellis, I. J. Martin, M. S. Lennard, and G. T. Tucker, "1-methyl-4-phenyl-1,2,3,6-tetrahydropyridine (MPTP) is $N$-demethylated by cytochromes P450 2D6, 1A2 and 3A4-implications for susceptibility to Parkinson's disease," Journal of Pharmacology and Experimental Therapeutics, vol. 277, no. 2, pp. 685-690, 1996.

[20] M. A. Collins and E. J. Neafsey, “ $\beta$-carboline analogues of $N$ methyl-4-phenyl-1,2,5,6-tetrahydropyridine (MPTP): endogenous factors underlying idiopathic parkinsonism?" Neuroscience Letters, vol. 55, no. 2, pp. 179-184, 1985.

[21] T. Herraiz, " $\beta$-carbolines as neurotoxins," in Isoquinolines and $\beta$-Carbolines as Neurotoxins and Neuroprotectants: New Vistas in Parkinson's Disease Therapy, L. Antkiewicz-Michaluk and H. Rommelspacher, Eds., vol. 1 of Current Topics in Neurotoxicity, pp. 77-103, Springer, 2012.

[22] T. Herraiz, "Relative exposure to $\beta$-carbolines norharman and harman from foods and tobacco smoke," Food Additives and Contaminants, vol. 21, no. 11, pp. 1041-1050, 2004.

[23] E. S. J. Robinson, N. J. Anderson, J. Crosby, D. J. Nutt, and A. L. Hudson, "Endogenous $\beta$-carbolines as clonidine-displacing substances," Annals of the New York Academy of Sciences, vol. 1009, pp. 157-166, 2003.

[24] T. Herraiz and C. Chaparro, "Human monoamine oxidase is inhibited by tobacco smoke: $\beta$-carboline alkaloids act as potent and reversible inhibitors," Biochemical and Biophysical Research Communications, vol. 326, no. 2, pp. 378-386, 2005.

[25] T. Herraiz and C. Chaparro, "Human monoamine oxidase enzyme inhibition by coffee and $\beta$-carbolines norharman and harman isolated from coffee," Life Sciences, vol. 78, no. 8, pp. 795-802, 2006.

[26] M. M. Airaksinen and I. Kari, “ $\beta$-carbolines, psychoactive compounds in the mammalian body-part I: occurrence, origin and metabolism," Medical Biology, vol. 59, no. 1, pp. 21-34, 1981.

[27] T. Herraiz and J. Galisteo, "Tetrahydro- $\beta$-carboline alkaloids occur in fruits and fruit juices. Activity as antioxidants and radical scavengers," Journal of Agricultural and Food Chemistry, vol. 51, no. 24, pp. 7156-7161, 2003.

[28] T. Herraiz, "Occurrence of 1,2,3,4-tetrahydro- $\beta$-carboline-3carboxylic acid and 1-methyl-1,2,3,4-tetrahydro- $\beta$-carboline-3carboxylic acid in fruit juices, purees, and jams," Journal of Agricultural and Food Chemistry, vol. 46, no. 9, pp. 3484-3490, 1998.

[29] D. A. Gearhart, M. A. Collins, J. M. Lee, and E. J. Neafsey, "Increased $\beta$-carboline $9 \mathrm{~N}$-methyltransferase activity in the frontal cortex in Parkinson's disease," Neurobiology of Disease, vol. 7, no. 3, pp. 201-211, 2000.

[30] C. Wernicke, Y. Schott, C. Enzensperger, G. Schulze, J. Lehmann, and H. Rommelspacher, "Cytotoxicity of $\beta$-carbolines in dopamine transporter expressing cells: structure-activity relationships," Biochemical Pharmacology, vol. 74, no. 7, pp. 1065-1077, 2007.

[31] S. Pavlovic, G. Schulze, C. Wernicke et al., "2,9-dimethyl- $\beta$-carbolinium, a neurotoxin occurring in human brain, is a potent inducer of apoptosis as 1-methyl-4-phenylpyridinium," Neuroscience, vol. 139, no. 4, pp. 1525-1537, 2006. 
[32] E. Lorenc-Koci, H. Rommelspacher, G. Schulze et al., "Parkinson's disease-like syndrome in rats induced by 2,9 -dimethyl- $\beta$ carbolinium ion, a $\beta$-carboline occurring in the human brain," Behavioural Pharmacology, vol. 17, no. 5-6, pp. 463-473, 2006.

[33] A. Storch, Y.-I. Hwang, D. A. Gearhart et al., "Dopamine transporter-mediated cytotoxicity of $\beta$-carbolinium derivatives related to Parkinson's disease: relationship to transporter-dependent uptake," Journal of Neurochemistry, vol. 89, no. 3, pp. 685-694, 2004.

[34] K. Matsubara, M. A. Collins, A. Akane et al., "Potential bioactivated neurotoxicants, $N$-methylated $\beta$-carbolinium ions, are present in human brain," Brain Research, vol. 610, no. 1, pp. 9096, 1993.

[35] K. Matsubara, S. Kobayashi, Y. Kobayashi et al., “ $\beta$-carbolinium cations, endogenous $\mathrm{MPP}^{+}$analogs, in the lumbar cerebrospinal fluid of patients with Parkinson's disease," Neurology, vol. 45, no. 12, pp. 2240-2245, 1995.

[36] K. Matsubara, T. Gonda, H. Sawada et al., "Endogenously occurring $\beta$-carboline induces parkinsonism in nonprimate animals: a possible causative protoxin in idiopathic Parkinson's disease," Journal of Neurochemistry, vol. 70, no. 2, pp. 727-735, 1998.

[37] M. B. H. Youdim, D. Edmondson, and K. F. Tipton, "The therapeutic potential of monoamine oxidase inhibitors," Nature Reviews Neuroscience, vol. 7, no. 4, pp. 295-309, 2006.

[38] M. Naoi, W. Maruyama, and K. Inaba-Hasegawa, “Type A and $\mathrm{B}$ monoamine oxidase in age-related neurodegenerative disorders: their distinct roles in neuronal death and survival," Current Topics in Medicinal Chemistry, vol. 12, no. 20, pp. 21772188, 2012.

[39] C. A. Lieu, S. J. Chinta, A. Rane, and J. K. Andersen, "Age-related behavioral phenotype of an astrocytic monoamine oxidase-B transgenic mouse model of Parkinson's Disease," PLoS ONE, vol. 8, no. 1, article e54200, 2013.

[40] O. Weinreb, T. Amit, O. Bar-Am, and M. B. H. Youdim, "Rasagiline: a novel anti-Parkinsonian monoamine oxidase-B inhibitor with neuroprotective activity," Progress in Neurobiology, vol. 92, no. 3, pp. 330-344, 2010.

[41] J. K. Mallajosyula, D. Kaur, S. J. Chinta et al., "MAO-B elevation in mouse brain astrocytes results in Parkinson's pathology," PLoS ONE, vol. 3, no. 2, article e1616, 2008.

[42] A.-M. Yu, J. R. Idle, L. G. Byrd, K. W. Krausz, A. Küpfer, and F. J. Gonzalez, "Regeneration of serotonin from 5-methoxytryptamine by polymorphic human CYP2D6," Pharmacogenetics, vol. 13, no. 3, pp. 173-181, 2003.

[43] A.-M. Yu, J. R. Idle, T. Herraiz, A. Küpfer, and F. J. Gonzalez, "Screening for endogenous substrates reveals that CYP2D6 is a 5-methoxyindolethylamine $O$-demethylase," Pharmacogenetics, vol. 13, no. 6, pp. 307-319, 2003.

[44] S. J. McCann, S. M. Pond, K. M. James, and D. G. le Couteur, "The association between polymorphisms in the cytochrome P450 2D6 gene and Parkinson's disease: a case-control study and meta-analysis," Journal of the Neurological Sciences, vol. 153, no. 1, pp. 50-53, 1997.

[45] A. Elbaz, C. Levecque, J. Clavel et al., "CYP2D6 polymorphism, pesticide exposure, and Parkinson's disease," Annals of Neurology, vol. 55, no. 3, pp. 430-434, 2004.

[46] A. Mann and R. F. Tyndale, "Cytochrome P450 2D6 enzyme neuroprotects against 1-methyl-4-phenylpyridinium toxicity in
SH-SY5Y neuronal cells," European Journal of Neuroscience, vol. 31, no. 7, pp. 1185-1193, 2010.

[47] S. Tafazoli and P. J. O’Brien, "Peroxidases: a role in the metabolism and side effects of drugs," Drug Discovery Today, vol. 10, no. 9, pp. 617-625, 2005.

[48] P. S. Green, A. J. Mendez, J. S. Jacob et al., "Neuronal expression of myeloperoxidase is increased in Alzheimer's disease," Journal of Neurochemistry, vol. 90, no. 3, pp. 724-733, 2004.

[49] D.-K. Choi, S. Pennathur, C. Perier et al., "Ablation of the inflammatory enzyme myeloperoxidase mitigates features of Parkinson's disease in mice," Journal of Neuroscience, vol. 25, no. 28, pp. 6594-6600, 2005.

[50] S. H. Huh, Y. C. Chung, Y. Piao et al., "Ethyl pyruvate rescues nigrostriatal dopaminergic neurons by regulating glial activation in a mouse model of Parkinson's disease," Journal of Immunology, vol. 187, no. 2, pp. 960-969, 2011.

[51] L. Galzigna, M. P. Schiappelli, A. Rigo, and M. Scarpa, "A rat brain fraction and different purified peroxidases catalyzing the formation of dopaminochrome from dopamine," Biochimica et Biophysica Acta, vol. 1427, no. 3, pp. 329-336, 1999.

[52] J. Everse and P. W. Coates, "Role of peroxidases in Parkinson disease: a hypothesis," Free Radical Biology and Medicine, vol. 38, no. 10, pp. 1296-1310, 2005.

[53] W. Jantschko, P. G. Furtmüller, M. Allegra et al., "Redox intermediates of plant and mammalian peroxidases: a comparative transient-kinetic study of their reactivity toward indole derivatives," Archives of Biochemistry and Biophysics, vol. 398, no. 1, pp. 12-22, 2002.

[54] T. Herraiz and H. Guillén, "Inhibition of the bioactivation of the neurotoxin MPTP by antioxidants, redox agents and monoamine oxidase inhibitors," Food and Chemical Toxicology, vol. 49, no. 8, pp. 1773-1781, 2011.

[55] R. E. Heikkila, L. Manzino, F. S. Cabbat, and R. C. Duvoisin, "Protection against the dopaminergic neurotoxicity of 1-methyl-4-phenyl-1,2,5,6-tetrahydropyridine by monoamine oxidase inhibitors," Nature, vol. 311, no. 5985, pp. 467-469, 1984.

[56] T. Herraiz, "Evaluation of the oxidation of 1-methyl-4-phenyl1,2,3,6-tetrahydropyridine (MPTP) to toxic pyridinium cations by monoamine oxidase (MAO) enzymes and its use to search for new MAO inhibitors and protective agents," Journal of Enzyme Inhibition and Medicinal Chemistry, vol. 27, no. 6, pp. 810-817, 2012.

[57] D. A. di Monte, E. Y. Wu, I. Irwin, L. E. Delanney, and J. W. Langston, "Biotransformation of 1-methyl-4-phenyl-1,2,3,6tetrahydropyridine in primary cultures of mouse astrocytes," Journal of Pharmacology and Experimental Therapeutics, vol. 258, no. 2, pp. 594-600, 1991.

[58] L. A. Peterson, P. S. Caldera, A. Trevor, K. Chiba, and N. Castagnoli Jr., "Studies on the 1-methyl-4-phenyl-2,3-dihydropyridinium species $2,3-\mathrm{MPDP}^{+}$, the monoamine oxidase catalyzed oxidation product of the nigrostriatal toxin 1-methyl-4-phenyl-1,2,3,6-tetrahydropyridine (MPTP)," Journal of Medicinal Chemistry, vol. 28, no. 10, pp. 1432-1436, 1985.

[59] T. Herraiz and J. Galisteo, "Tetrahydro- $\beta$-carboline alkaloids that occur in foods and biological systems act as radical scavengers and antioxidants in the ABTS assay," Free Radical Research, vol. 36, no. 8, pp. 923-928, 2002.

[60] F. J. Jimenez-Jimenez, C. Tabernero, M. A. Mena et al., "Acute effects of 1-methyl-4-phenyl-1,2,3,6-tetrahydropyridine in a 
model of rat designated a poor metabolizer of debrisoquine," Journal of Neurochemistry, vol. 57, no. 1, pp. 81-87, 1991.

[61] H. Inoue, K. Castagnoli, C. van der Schyf, S. Mabic, K. Igarashi, and N. Castagnoli Jr., "Species-dependent differences in monoamine oxidase A and B-catalyzed oxidation of various C4 substituted 1-methyl-4-phenyl-1,2,3,6- tetrahydropyridinyl derivatives," Journal of Pharmacology and Experimental Therapeutics, vol. 291, no. 2, pp. 856-864, 1999.

[62] J. Everse, C.-J. J. Liu, and P. W. Coates, "Physical and catalytic properties of a peroxidase derived from cytochrome c," Biochimica et Biophysica Acta, vol. 1812, no. 9, pp. 1138-1145, 2011.

[63] D. L. Lefkowitz and S. S. Lefkowitz, "Microglia and myeloperoxidase: a deadly partnership in neurodegenerative disease," Free Radical Biology and Medicine, vol. 45, no. 5, pp. 726-731, 2008.

[64] A. Mann, S. L. Miksys, A. Gaedigk, S. J. Kish, D. C. Mash, and R. F. Tyndale, "The neuroprotective enzyme CYP2D6 increases in the brain with age and is lower in Parkinson's disease patients," Neurobiology of Aging, vol. 33, no. 9, pp. 2160-2171, 2012.

[65] T. L. Perry, K. Jones, S. Hansen, and R. A. Wall, “4-phenylpyridine and three other analogues of 1-methyl-4-phenyl-1,2,3,6tetrahydropyridine lack dopaminergic nigrostriatal neurotoxicity in mice and marmosets," Neuroscience Letters, vol. 75, no. 1, pp. 65-70, 1987.

[66] T. Herraiz, D. González, C. Ancín-Azpilicueta, V. J. Arán, and H. Guillén, " $\beta$-carboline alkaloids in Peganum harmala and inhibition of human monoamine oxidase (MAO)," Food and Chemical Toxicology, vol. 48, no. 3, pp. 839-845, 2010.

[67] T. Herraiz, "Tetrahydro- $\beta$-carboline-3-carboxylic acid compounds in fish and meat: possible precursors of co-mutagenic $\beta$-carbolines norharman and harman in cooked fools," Food Additives and Contaminants, vol. 17, no. 10, pp. 859-866, 2000.

[68] E. D. Louis, E. Rios, K. M. Pellegrino, W. Jiang, P. FactorLitvak, and W. Zheng, "Higher blood harmane (1-methyl9H-pyrido[3,4-b]indole) concentrations correlate with lower olfactory scores in essential tremor," NeuroToxicology, vol. 29, no. 3, pp. 460-465, 2008.

[69] K. Matsubara, M. A. Collins, and E. J. Neafsey, "Mono- $N$-methylation of 1,2,3,4-tetrahydro- $\beta$-carbolines in brain cytosol: absence of indole methylation," Journal of Neurochemistry, vol. 59, no. 2, pp. 505-510, 1992.

[70] S. A. Barker, R. E. W. Harrison, J. A. Monti, G. B. Brown, and S. T. Christian, "Identification and quantification of 1,2,3,4-tetrahydro- $\beta$-carboline, 2 -methyl-1,2,3,4-tetrahydro- $\beta$ carboline and 6-methoxy-1,2,3,4-tetrahydro- $\beta$-carboline as in vivo constituents of rat brain and adrenal gland," Biochemical Pharmacology, vol. 30, no. 1, pp. 9-17, 1981.

[71] J. Hamann, H. Rommelspacher, A. Storch, H. Reichmann, and G. Gille, "Neurotoxic mechanisms of 2,9-dimethyl- $\beta$ carbolinium ion in primary dopaminergic culture," Journal of Neurochemistry, vol. 98, no. 4, pp. 1185-1199, 2006. 

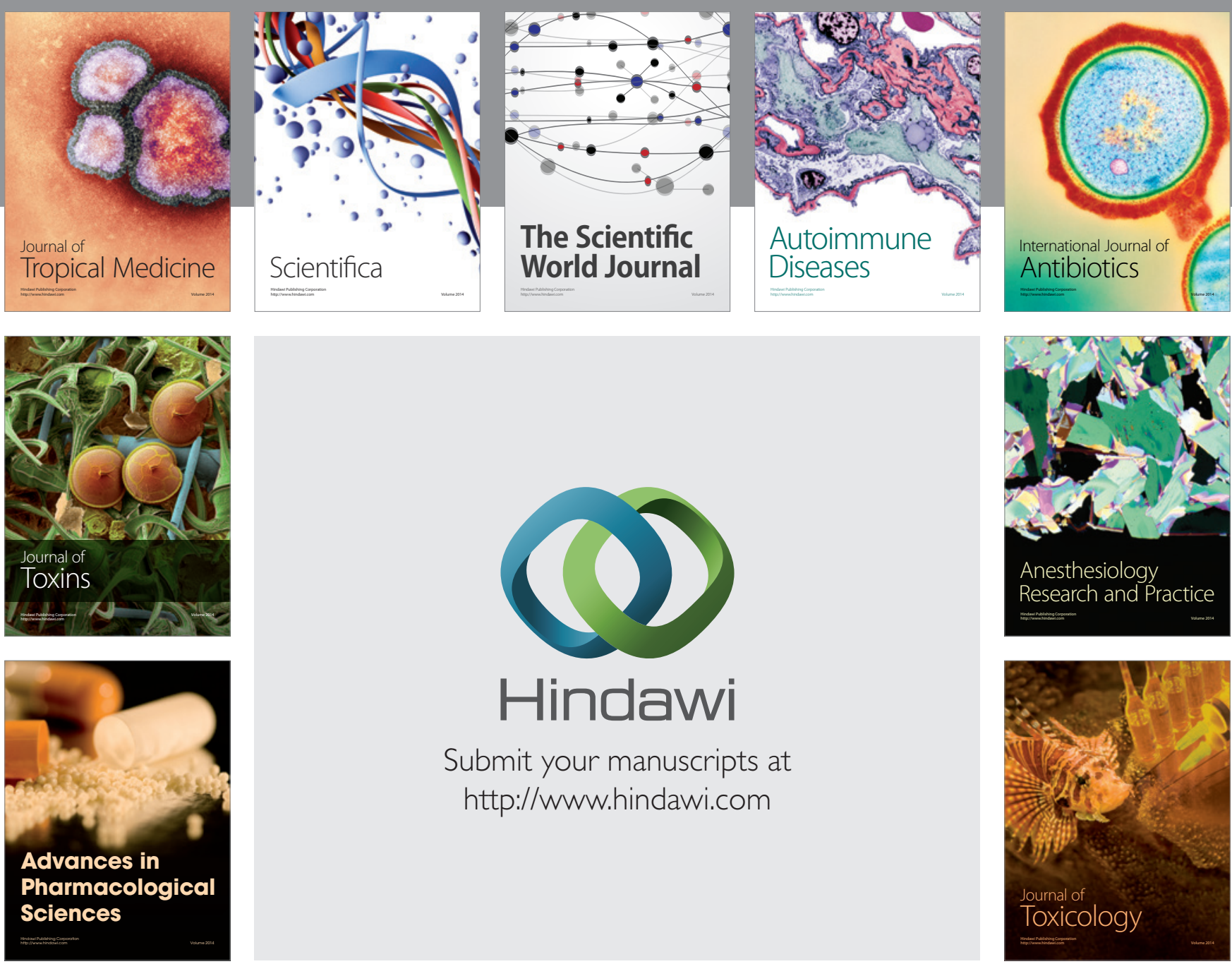

\section{Hindawi}

Submit your manuscripts at

http://www.hindawi.com
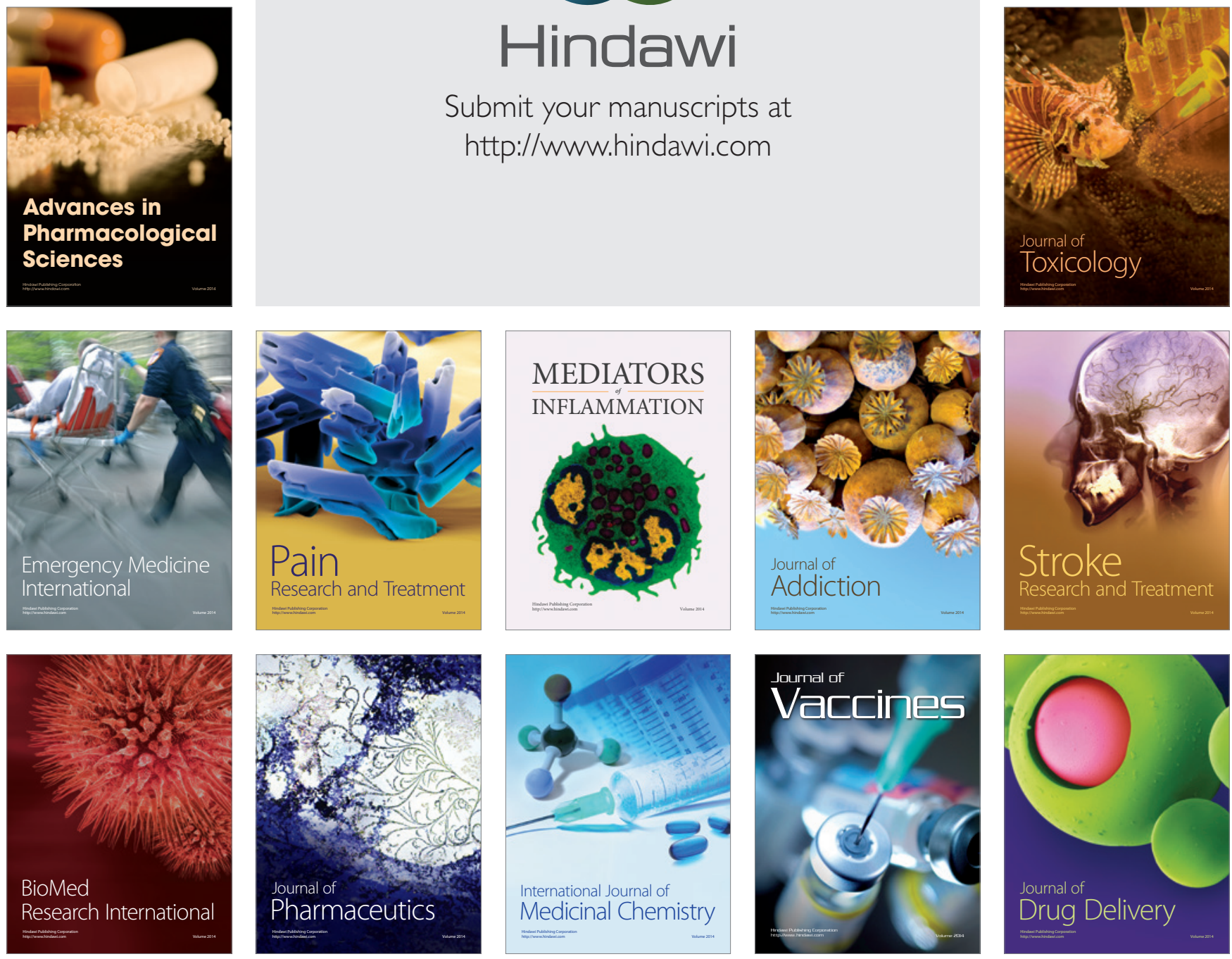